\title{
Slow Formation of Pseudorotaxanes in Water
}

\author{
Yves Aeschi, ${ }^{[a, b]}$ Laurent Jucker, ${ }^{[a]}$ Daniel Häussinger ${ }^{[a]}$ and Marcel Mayor ${ }^{*[a, b, c, d]}$ \\ Dedicated to Prof. Gottfried Schill as visionary pioneer and mastermind of mechanically interlocked superstructures
}

\begin{abstract}
The synthesis of two water-soluble oligophenyleneethynylene (OPE)-rods with substituted iso- and terephthalate end groups is presented. Both undergo slow association with a Diederichtype cyclophane in aqueous solution. Formation of [2]pseudorotaxanes occurs with reaction half-lives of several hours. Characterization of the supermolecules by ${ }^{1} \mathrm{H}-\mathrm{NMR}$ spectroscopy reveals a high thermodynamic stability and kinetic inertness of the pseudorotaxanes. The phthalate precursors are functionalized with peripheral azide groups, which make them modular precursors for construction of mechanically interlocked molecules in water.
\end{abstract}

\section{Introduction}

For the realization of catenane- and (pseudo)rotaxane-based molecular pumps or directional motors, ratchet mechanisms can be employed to achieve directionality. ${ }^{[1-3]}$ Control over kinetics and thermodynamics of host-guest association and/or interconversion of translational isomers is required for this purpose. ${ }^{[4-9]}$ Whereas the choice of a certain recognition motif dictates thermodynamic strength of association in host-guest systems often in an intuitive way, the kinetics of their formation is usually less straight forward to predict. Steric interactions are frequently used for this purpose,${ }^{[10-14]}$ although electrostatic repulsion ${ }^{[15]}$ or attraction ${ }^{[16]}$ may also be engaged. Incremental variation of steric factors is often required to reveal design rules for rational adjustment of exchange kinetics. ${ }^{[10-14]}$ The factors controlling exchange kinetics are highly specific to the host/guest combination. This was initially observed in the "slipping" assembly of rotaxanes, ${ }^{[10,11,17,18]}$ for which a stopper unit must be tailored such that it is insurmountable at ambient conditions, but can be overcome

[a] Y. Aeschi, L. Jucker, PD Dr. D. Häussinger, Prof. Dr. M. Mayor Department of Chemistry University of Basel St. Johanns-Ring 19 4056 Basel, Switzerland E-mail: marcel.mayor@unibas.ch www.chemie.unibas.ch/ mayor

[b] Y. Aeschi, Prof. Dr. M. Mayor Swiss Nanoscience Institute University of Basel Klingelbergstrasse 82 4056 Basel, Switzerland

[c] Prof. Dr. M. Mayor Institute for Nanotechnology (INT) Karlsruhe Institute of Technology (KIT) P. O. Box 3640 76021 Karlsruhe, Germany

[d] Prof. Dr. M. Mayor Lehn Institute of Functional Materials (LIFM) School of Chemistry Sun Yat-Sen University (SYSU)

Guangzhou 510275, China

Supporting information for this article is given via a link at the end of the document by applying heat or pressure. It has already been discussed that the identity as rotaxane or pseudorotaxane is not clearly defined and may become a matter of definition, ${ }^{[19]}$ depending on its kinetic inertness at a given set of conditions.

Rigid and extended $\pi$-conjugated guests were rarely integrated into (pseudo)rotaxane systems exhibiting slow assembly or slipping processes. ${ }^{[20,21]}$ This is in part certainly due to their low solubility and the resulting necessity of attaching solubilizing groups. These may interfere with the host/guest assembly formation and pose additional synthetic efforts. An elegant way to circumvent these limitations is the intramolecular slipping approach for the synthesis of [1]rotaxanes. ${ }^{[22]}$ This enabled the assembly of oligophenyleneethynylene (OPE)-type insulated wires with remarkable properties. ${ }^{[23-26]}$

The aim of this work was the synthesis of highly watersoluble OPE rods, which exhibit high association strength towards Diederich-type cyclophanes. ${ }^{[27-29]}$ Naphthalene ${ }^{[30-33]}$ and OPEbased ${ }^{[34-36]}$ guests have shown to bind strongly to 4 (Scheme 1). We recently presented the synthesis of daisy chains based on a salicylate-terminated OPE rod and a cyclophane derived from 4. ${ }^{36]}$ Slow exchange on the ${ }^{1} \mathrm{H}-\mathrm{NMR}$ timescale $(500 \mathrm{MHz})$ was observed, however both the daisy chains and mixtures of the model compounds $\mathbf{4}$ and $\mathbf{3}$ equilibrated within less than a few minutes, such that complex formation could not be observed by time-dependent ${ }^{1} \mathrm{H}$-NMR spectroscopy. By replacing the salicylate moiety with a sterically more demanding end-group, even lower exchange rates should be achieved. In addition, the resulting OPE rods must be suitable for integration into larger, mechanically bonded assemblies. Copper(I)-catalyzed azidealkyne cycloaddition click-chemistry (CuAAC) ${ }^{[37]}$ is ideal for this purpose, therefore the guest axles presented herein are terminally functionalized with azide groups similar to $\mathbf{3}$. The synthetic challenge was to find a reasonably compact design of the substitution pattern, which integrates a kinetic barrier, solubilizing groups, azide functionality and a leaving group for $\mathrm{Pd}^{0}$-catalyzed cross-coupling reactions into a single precursor. Substituted iso- and terephthalate derivatives were identified as interesting building blocks for this purpose, providing synthetic accessibility in combination with the desired compact substitution pattern. The synthesis and characterization of two OPE rods incorporating such a compact phthalate-based moiety is presented herein. The binding strength and association kinetics are evaluated and compared to the previously reported OPE rod 3. 

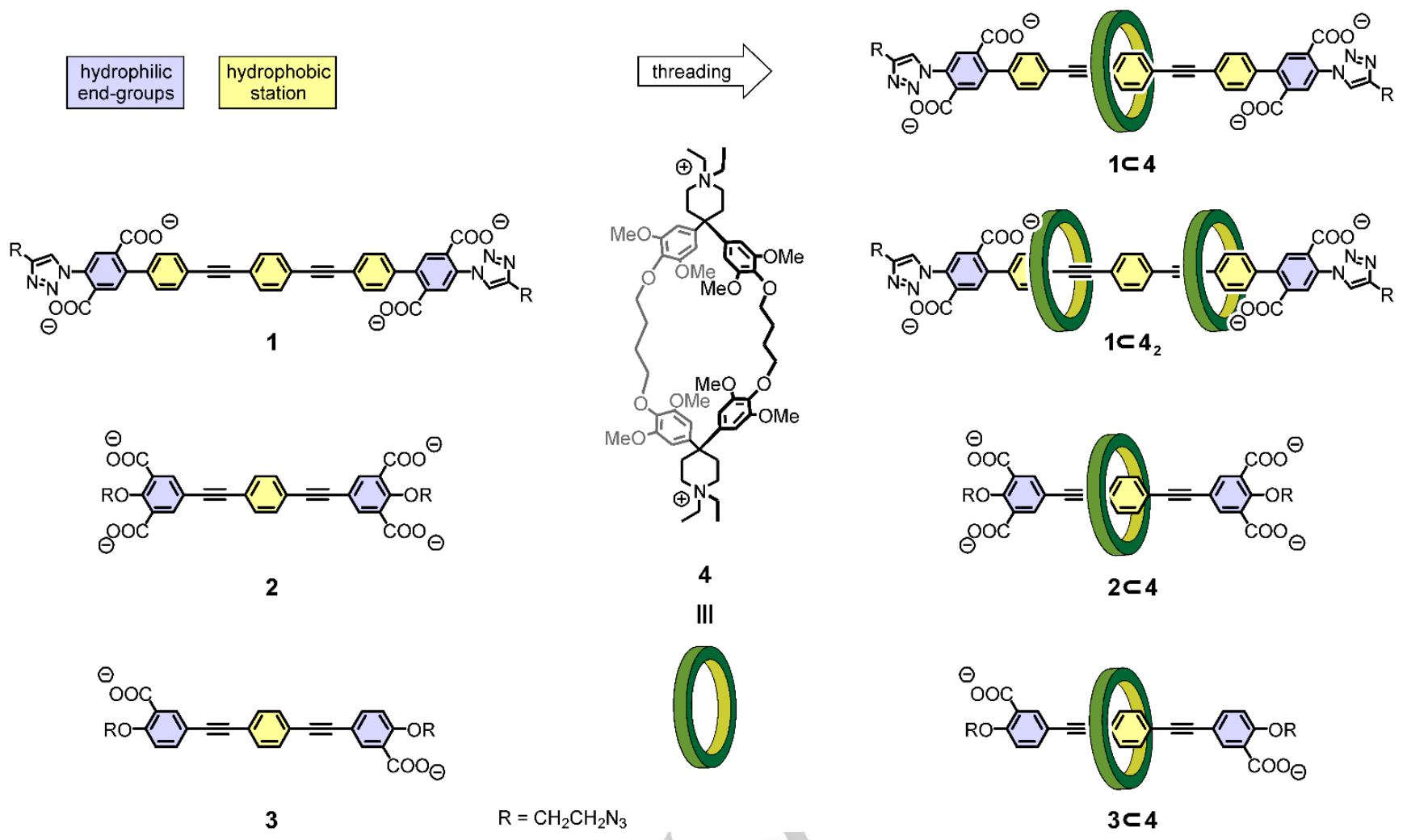

Scheme 1. Conceptual assembly of pseudorotaxanes from OPE rods 1, 2, 3 and cyclophane 4 .

\section{Results and Discussion}

The conceptual design of the OPE rods 1 and 2 resembles the one of the already reported dicarboxylate rod 3. A central hydrophobic station is squeezed between solubilizing end-groups, which carry an additional azide substituent enabling further functionalization by CuAAC. Aliphatic spacers were introduced between the aromatic unit and the azide groups as m-extended aromatic azides are known for their photosensitivity. ${ }^{[38,39]} \mathrm{A}$ central 1,4-substituted phenylene moiety is either linked to the phthalate moiety via ethynylene or 4-phenylethynylene linkers. The additional phenylene moiety in $\mathbf{1}$ serves to avoid potential stability issues with $o$-carboxy-substituted phenylacetylenes.

Terephthalate-based OPE rod 1 was synthesized starting from commercially available dimethyl-2-aminoterephthalate (see Scheme 2). Iodination with NIS in $\mathrm{MeOH} / \mathrm{DCM}$ proceeded smoothly to give $\mathbf{5}$ in a yield of $74 \%$. In the following step, a diazotation/azidation protocol using $t$-BuONO and $\mathrm{TMSN}_{3}{ }^{[40]}$ in acetonitrile was employed, which led to a clean transformation to azide 6 in a yield of $97 \%$ after recrystallization. The aromatic azide group was transformed into a triazole moiety by CUAAC with 3-butyn-1-ol, giving 7 in $86 \%$ yield. The classical "click" conditions with sodium ascorbate and $\mathrm{CuSO}_{4}$ in this case led to partial deiodination, probably due to the strong activation of the iodosubstituent ortho to the carboxylate. This was prevented by using $2 \mathrm{~mol} \%$ TBTA and $\mathrm{Cu}\left(\mathrm{CH}_{3} \mathrm{CN}\right)_{4} \mathrm{PF}_{6}$, avoiding the presence of a reducing agent. The hydroxyl group was transformed to the alkyl bromide by an Appel-reaction to give 8 in $93 \%$ yield. Nucleophilic substitution with sodium azide in DMF proceeded smoothly to give 9 in $94 \%$ yield after short chromatographic purification.

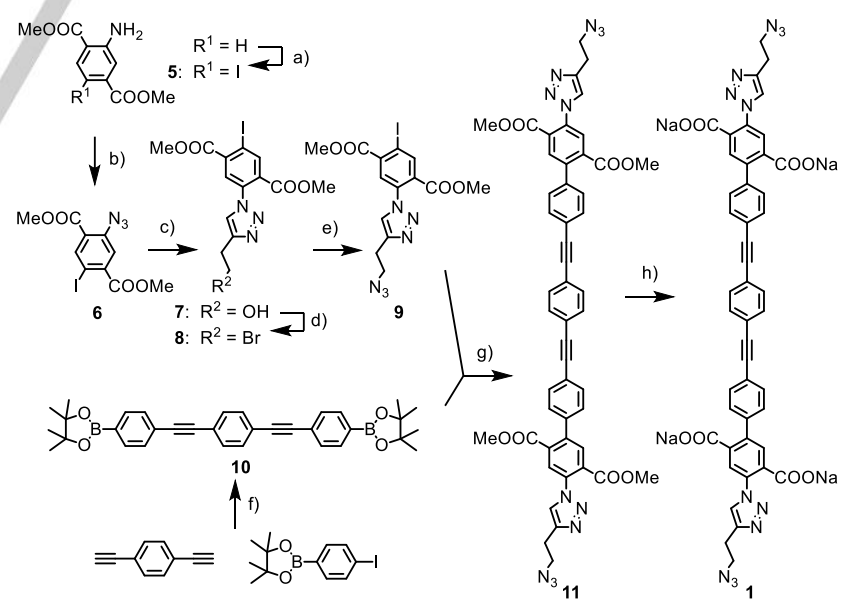

Scheme 2. a) NIS, MeOH/DCM 1:1, reflux, 16 h, $74 \%$; b) $t$-BuONO, TMSN $\mathrm{CH}_{3} \mathrm{CN}, 0^{\circ} \mathrm{C}, 1 \mathrm{~h}, 97 \%$; c) 3-butyn-1-ol, $\mathrm{Cu}\left(\mathrm{CH}_{3} \mathrm{CN}\right)_{4} \mathrm{PF}_{6}, \mathrm{TBTA} \mathrm{CH}_{3} \mathrm{CN}$, r.t., $86 \%$; d) $\mathrm{CBr}_{4}, \mathrm{Ph}_{3} \mathrm{P}$, THF, $-20^{\circ} \mathrm{C}$ to r.t., $6 \mathrm{~h}, 93 \%$; e) $\mathrm{NaN}_{3}$, DMF, $50{ }^{\circ} \mathrm{C}, 18 \mathrm{~h}$, $94 \%$; f) $\mathrm{Pd}\left(\mathrm{PPh}_{3}\right)_{2} \mathrm{Cl}_{2}$, Cul, Et 3 N/THF 1:2, r.t., 20 h, $83 \%$; g) Pd(dppf) $\mathrm{Cl}_{2}{ }^{*} \mathrm{CH}_{2} \mathrm{Cl}_{2}$, $\mathrm{Na}_{2} \mathrm{CO}_{3}, \mathrm{PhMe} / \mathrm{H}_{2} \mathrm{O} 5: 1,80^{\circ} \mathrm{C}, 4 \mathrm{~h}, 57 \%$; h) $\mathrm{NaOH}$, THF/MeOH$/ \mathrm{H}_{2} \mathrm{O}$ 5:5:1, $60{ }^{\circ} \mathrm{C}, 30 \mathrm{~min}, 82 \%$. 
The central OPE unit $\mathbf{1 0}$ was obtained by Sonogashira crosscoupling of 4-iodophenylboronic acid pinacol ester with 1,4-diethynylbenzene, yielding $83 \%$ of the desired compound after crystallization. Suzuki cross-coupling of $\mathbf{9}$ and $\mathbf{1 0}$ using $\mathrm{Pd}(\mathrm{dppf}) \mathrm{Cl}_{2}{ }^{*} \mathrm{CH}_{2} \mathrm{Cl}_{2}$ as precatalyst yielded 11 in $57 \%$ yield. After saponification of the methyl esters with $\mathrm{NaOH}, \mathbf{1}$ was obtained in $82 \%$ yield.

The synthesis of the rod 2 is displayed in scheme 3 . The isophthalate moiety was obtained from 2-hydroxyisophthalic acid by a one-pot iodination/Fischer esterification procedure in methanol using first NIS, followed by the addition of $\mathrm{H}_{2} \mathrm{SO}_{4}$. This provided 12 in $54 \%$ yield after crystallization from the reaction mixture. The following alkylation of the phenolic hydroxyl group with 1-bromo-2-chloroethane in DMSO in presence of $\mathrm{Cs}_{2} \mathrm{CO}_{3}$ proceeded in a clean conversion to give 13 in $96 \%$ yield. Nucleophilic substitution with $\mathrm{NaN}_{3}$ in $\mathrm{DMSO}$ at $60^{\circ} \mathrm{C}$ proceeded cleanly as well, only requiring extraction for purification to provide 14 in $96 \%$ yield. Sonogashira cross-coupling to 1,4-diethynylbenzene proceeded efficiently at room temperature, to give $82 \%$ of $\mathbf{1 5}$ after crystallization. Final saponification of the methyl esters with $\mathrm{NaOH}$ in a mixture of $\mathrm{THF} / \mathrm{MeOH} / \mathrm{H}_{2} \mathrm{O}$ gave OPE 2 in $78 \%$ yield. Both OPE rods $\mathbf{1}$ and $\mathbf{2}$ exposing four carboxylates contain residual solvents and/or traces of salts (sodium bicarbonate in 2), which we were not able to remove in spite of numerous purification attempts. To maintain reasonable control over the stoichiometry, the samples were dried under vacuum and the content of the desired rod per weight of the sample was determined by ${ }^{1} \mathrm{H}-\mathrm{NMR}$ and elemental analysis. The investigation revealed product contents of $88 \%$ for $\mathbf{1}$ and $91 \%$ for 2 .

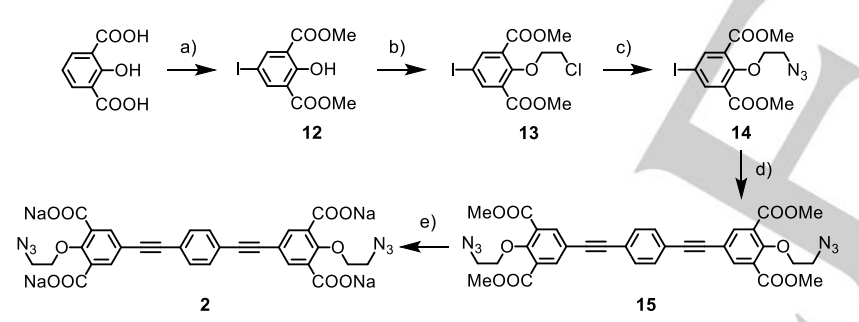

Scheme 3. a) $\mathrm{NIS}, \mathrm{MeOH}$, r.t., 16 h, then $\mathrm{H}_{2} \mathrm{SO}_{4}$, reflux, 10 h, 54 \%; b) 1-bromo2-chloroethane, $\mathrm{Cs}_{2} \mathrm{CO}_{3}$, DMSO, r.t., 16 h, $96 \%$; c) $\mathrm{NaN}_{3}, \mathrm{DMSO}, 60^{\circ} \mathrm{C}, 20 \mathrm{~h}$, $96 \%$; d) 1,4-diethynylbenzene, $\mathrm{Pd}\left(\mathrm{PPh}_{3}\right)_{2} \mathrm{Cl}_{2}$, Cul, Et ${ }_{3} \mathrm{~N} / \mathrm{THF} 1: 6$, r.t., 14 h, $82 \%$; e) $\mathrm{NaOH}$, THF/MeOH$/ \mathrm{H}_{2} \mathrm{O} 4: 4: 1,60^{\circ} \mathrm{C}, 1 \mathrm{~h}, 78 \%$.

Upon complexation of the aromatic moieties of 1 and 2 by the cyclophane 4, an upfield shift of 2-2.5 ppm was expected for encircled protons. ${ }^{[30,34,35]}$ Indeed, when 4 was added to solutions of 1 and 2 in $\mathrm{D}_{2} \mathrm{O}$, signals between 5.0 and $6.0 \mathrm{ppm}$ slowly started to appear within minutes to a few hours (Figures 1 and 3 ). This process was considerably accelerated by higher temperatures. Complexation studies to determine stoichiometry were performed at $0.5 \mathrm{mM}$ host/guest concentration in $\mathrm{D}_{2} \mathrm{O}$. The chosen concentration window was an optimized compromise where no precipitation was observed visually and sharp signals were still observed in the ${ }^{1} \mathrm{H}$-NMR spectra with an acceptable signal to noise ratio. Higher concentrations tended to precipitate host/guest conglomerates, most likely the neutral combinations of an OPE rod (1 or 2) with two molecules cyclophane 4 . Solutions of the OPE rod (1 or $\mathbf{2}$ ) with either 1, 2 or 5 equivalents of $\mathbf{4}$ were heated to $90{ }^{\circ} \mathrm{C}$ for $16 \mathrm{~h}$ and compared to the spectrum in absence of 4 (Figure 1).

a)

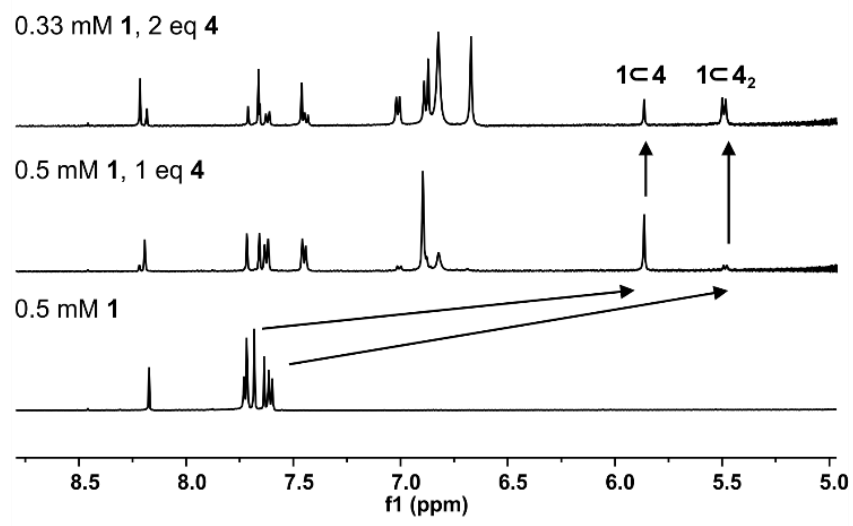

b)

$0.5 \mathrm{mM} 2,5$ eq 4

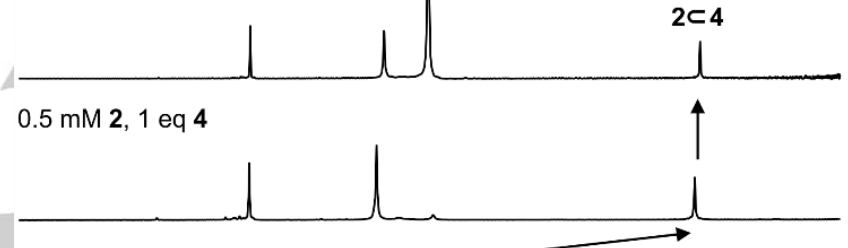

$0.5 \mathrm{mM} 2$

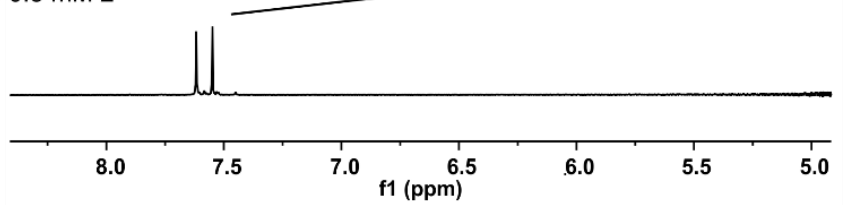

Figure 1. Distinct chemical shifts in the ${ }^{1} \mathrm{H}$-NMR spectra of a) $\mathbf{1}$ and b) 2 in the presence of various equivalents of 4 displaying the formation of the [2] / [3]pseudorotaxanes $\mathbf{1} \subset \mathbf{4}, \mathbf{1} \subset \mathbf{4}_{2}$, and $\mathbf{2} \subset \mathbf{4}$ respectively after heating. Arrows are guiding the eye to the most strongly shifted resonances.

For the terephthalate-terminated rod $\mathbf{1}$, mainly a 1:1 binding stoichiometry was observed when adding 1 equivalent of 4 with the phenylene resonance being shifted from 7.68 to $5.86 \mathrm{ppm}$. Upon addition of a 4 -fold excess of 4 , almost quantitative precipitation was observed instantaneously. This behavior is most likely due to the extended hydrophobic backbone of 1 , which results in an increased tendency to co-precipitate quickly with the relatively lipophilic dication 4 . Another intriguing consequence of the elongated backbone of $\mathbf{1}$ is its ability to form [3]pseudorotaxanes. Already in the $1: 1$ mixture of $\mathbf{1}$ and $\mathbf{4}$, a faint doublet at $5.49 \mathrm{ppm}$ points at the presence of the [3]pseudorotaxane 1с42. The doublet becomes more pronounced with increasing equivalents of $\mathbf{4}$ and in a spectrum of $\mathbf{1}(0.33 \mathrm{mM})$ in presence of 2 equivalents $4(0.66 \mathrm{mM})$, a ratio of $1: 3$ between $1 \subset 4$ and $1 \subset 42$ was determined by integration of ${ }^{1} \mathrm{H}-\mathrm{NMR}$ signals. Although very little precipitation was already observed in this sample, a $K_{\mathrm{a}}$ of $>10^{4} \mathrm{M}^{-1}$ for the second association process could be estimated from this single point measurement. The doublet coupling pattern reveals that $\mathbf{4}$ resides on the 1,4-subsituted phenylene moiety of the terminal biphenyl unit. This results in a large change of chemical shift from 
7.61 to $5.49 \mathrm{ppm}$, while the central phenylene unit of $\mathbf{1 \subset \mathbf { 4 } _ { 2 }}$ appears at about $6.9 \mathrm{ppm}$ with only moderate shift of about 0.8 ppm compared to the free rod 1. This observation supports the absence of an encircling cyclophane on the central phenylene subunit in $\mathbf{1} \subset \mathbf{4}$, which results from the mutual electrostatic repulsion of the receptors.

The situation becomes simpler for 2 , which is too short to accommodate more than one cyclophane on the axle. And indeed, exclusively a $1: 1$ binding stoichiometry at $0.5 \mathrm{mM}$ was observed by ${ }^{1} \mathrm{H}$-NMR regardless of the excess of 4 . Even with 5 equivalents of 4 , precipitation was not observed pointing at the more hydrophilic nature of $\mathbf{2}$. The cyclophane as host resides on the central phenylene subunit of the guest axle 2, which displays a change in chemical shift from 7.55 to $5.53 \mathrm{ppm}$. Overall, the behavior of 2 resembles the one of $\mathbf{3}^{[36]}$ from which $\mathbf{2}$ differs only by two additional carboxylate groups.

The positions of the cyclophane 4 on the axles 1 and 2 in their superstructures $\mathbf{1} \subset \mathbf{4}, \mathbf{2} \subset \mathbf{4}$, and $\mathbf{1} \subset \mathbf{4} \mathbf{2}$ were corroborated by the corresponding ${ }^{1} \mathrm{H}-\mathrm{NOESY}$ spectra. In particular, cross peaks between the protons of the axles' central phenylene unit and the cyclophane's aryl- and methoxy groups were observed for $\mathbf{1 \subset 4}$ and $\mathbf{2} \subset \mathbf{4}$. In the case of $\mathbf{1} \subset \mathbf{4}$, cross peaks of the cyclophane protons to the biphenyl protons confirmed the arrangement of both cyclophanes on the terminal biphenyl subunits of the axles.

Limited photostability of the rods $\mathbf{1}$ and $\mathbf{2}$ hampered the investigation of the superstructures by optical spectroscopy. The optical characterization was performed exclusively with freshly prepared samples and series of consecutive measurements were avoided. Both rods displayed comparable spectroscopic behavior upon formation of their superstructures (Figure 2). To guarantee the presence of the superstructures $1 \subset 4$ and $2 \subset 4$ respectively, the samples for optical spectroscopy were prepared by dilution of the already equilibrated $0.5 \mathrm{mM}$ NMR samples in $\mathrm{D}_{2} \mathrm{O}$ to concentrations of $1 \mu \mathrm{M}$. In their UV/VIS spectra, a slight decrease in signal intensity was observed upon complexation with 4 (16\% for 1 and $11 \%$ for 2 ). In the case of $\mathbf{2}$, an additional bathochromic shift of about $4 \mathrm{~nm}$ was observed upon formation of $2 \subset 4$. In their fluorescence spectra, a more pronounced reduction in intensity was observed upon formation of the superstructures. The fluorescence signal intensities of the superstructures $\mathbf{1} \subset \mathbf{4}$ and $\mathbf{2} \subset \mathbf{4}$ were reduced by $64 \%$ and $90 \%$ compared to the signals of the parent rods 1 and 2 . To assure that the reduced fluorescence is due to the formation of the superstructures, $1 \mu \mathrm{M}$ mixtures of the rods 1 or $\mathbf{2}$ and the cyclophane $\mathbf{4}$ were prepared and their fluorescence spectra were recorded immediately, before the pseudorotaxane could form. And indeed, the emission intensities resembled the ones of the pure samples of the rods 1 and 2 (Figures SI 14 and 15). After storing for $40 \mathrm{~h}$ in the dark, a reduced emission was recorded for both samples, pointing at the partial formation of the pseudorotaxanes $\mathbf{1 \subset 4}$ and $\mathbf{2 \subset 4}$. The lower fluorescence intensities upon encirclation with $\mathbf{4}$ compare well to a structurally related OPE-based rotaxane by Anderson et al. ${ }^{[35]}$ The rather small changes in optical properties upon formation of the rotaxanes point at weak electronic interactions of the mechanically interlinked components. Determination of association constants by either fluorescence- or UV-VIS-titration experiments in water was hampered by both the limited photostability of 1 and 2 and the low exchange rates with 4 . The latter also impeded measurements by isothermal titration calorimetry (ITC).

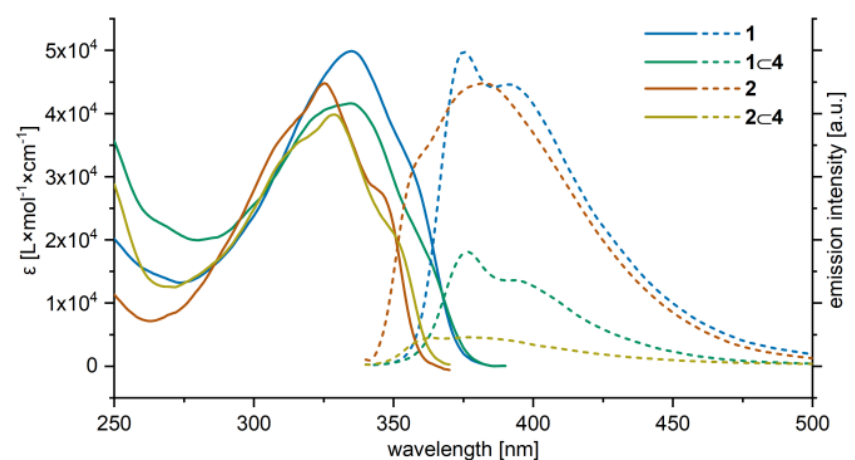

Figure 2. Absorption (left, solid lines) and emission (right, dotted lines) spectra of $1,2,1 \subset 4$, and $2 \subset 4$ at $1 \mu \mathrm{M}$ concentrations in water. Fluorescence intensities of 1 and 2 are normalized to their corresponding absorption maxima; Emission intensities of $\mathbf{1} \subset \mathbf{4}$ and $\mathbf{2 \subset 4}$ are displayed relative to the emission intensities of $\mathbf{1}$ and 2 respectively. The emission spectra were corrected for complexationinduced changes in absorption.

To get a hand on the association constants $\left(K_{a}\right)$ involved between the rods and the cyclophane, detailed ${ }^{1} \mathrm{H}$-NMR studies were performed. A dilution series of 1:1 mixtures of the rods (1 or 2 ) and the cyclophane 4 in $\mathrm{D}_{2} \mathrm{O}$ displayed still saturation at $10 \mu \mathrm{M}$ concentration, which is almost at the sensitivity limit of our ${ }^{1} \mathrm{H}-\mathrm{NMR}$ spectrometer. The measurements were thus performed with 0.5 $\mathrm{mM}$ concentrations in a methanol- $\mathrm{d}_{4} / \mathrm{D}_{2} \mathrm{O}(19 / 1)$ mixture, which reduces the binding strength considerably due to partial disruption of the hydrophobic effect. As a consequence of the methanol addition, the association constants are in a range observable by ${ }^{1} \mathrm{H}$-NMR experiments. ${ }^{[41]}$ The $K_{a}$ values were obtained from single point measurements of aged 1:1 mixtures of the rods 1-3 and $\mathbf{4}$, as the exchange dynamic was considerably slower than the time resolution of the experiment. Of particular interest was the $K_{a}$ of 1.6. $10^{3} \pm 100 \mathrm{M}^{-1}$ determined for the formation of the rotaxane $3 \subset 4$ in this solvent mixture, as the aggregation constant of this pseudorotaxane was also determined to be $4 \cdot 10^{6} \mathrm{M}^{-1}$ in pure water by ITC. ${ }^{[36]}$ The solvent shift from pure water to the methanol$d_{4} / D_{2} \mathrm{O}(19 / 1)$ mixture causes a loss of about three orders of magnitude in the association constant between $\mathbf{3}$ and $\mathbf{4}$, and the structural resemblance of $\mathbf{1}$ and $\mathbf{2}$ with $\mathbf{3}$ suggest comparable effects concerning their association with 4. Similar observations have been reported by Anderson et al. with an anionic OPE based rod structure and $4 .{ }^{[35]} \mathrm{A}$ comparable $K_{a}$ value of $3.5 \cdot 10^{3} \mathrm{M}^{-1}$ was obtained for the elongated terephthalate terminated rod 1 and the cyclophane 4 in the methanol- $d_{4} / D_{2} \mathrm{O}(19 / 1)$ mixture, while an increased $K_{a}$ of $9.0 \cdot 10^{3} \mathrm{M}^{-1}$ was recorded for the isophthalate terminated rod $\mathbf{2}$ with $\mathbf{4}$ under the same conditions. The stronger binding of the di-cationic host $\mathbf{4}$ on rod $\mathbf{2}$ compared to $\mathbf{1}$ probably reflects the improved electrostatic interactions. The anionic carboxylate groups of $\mathbf{2}$ are closer to the cationic subunits of the cyclophane than in the case of $\mathbf{1}$ and the increased association constant reflects the distance dependence of the Coulomb attraction.

In conclusion, the two dicarboxylate terminated rods $\mathbf{1}$ and 2 display binding strengths towards $\mathbf{4}$ which are at least comparable (1) or even higher (2) than 3. Interestingly, in the limited temperature range of a VT- ${ }^{-1} \mathrm{H}-\mathrm{NMR}$ experiment $\left(25-90{ }^{\circ} \mathrm{C}\right)$, the spectral features of the pseudorotaxane complexes did not display temperature dependence (Figures SI 6 and SI 10). This thermal insensitivity might comprise both, thermodynamic and 
kinetic contributions. While a temperature insensitive equilibrium constant thermodynamically would point at an entropically dominated driving force, the bulkiness of the terminal unit might kinetically disfavor the unthreading. The efficient pseudorotaxane formation at $90^{\circ} \mathrm{C}$ favors the kinetic reasoning, and the completeness of the process points at a high thermodynamic binding strength (Figures $1 \mathrm{a}$ and $\mathrm{b}$ ). A similar thermal insensitivity was also recorded for $\mathbf{3 \subset 4}$, and the sterically less demanding termini of $\mathbf{3}$ reduce the weight of the kinetic argument, at least in this case. However, even if the complexation should be purely thermodynamically driven, conclusions concerning its driving force (enthalpic or entropic) cannot be drawn from the thermal insensitivity of the ${ }^{1} \mathrm{H}$-NMR spectra, due to the minor effect on the association constant in the small experimentally accessible temperature range.
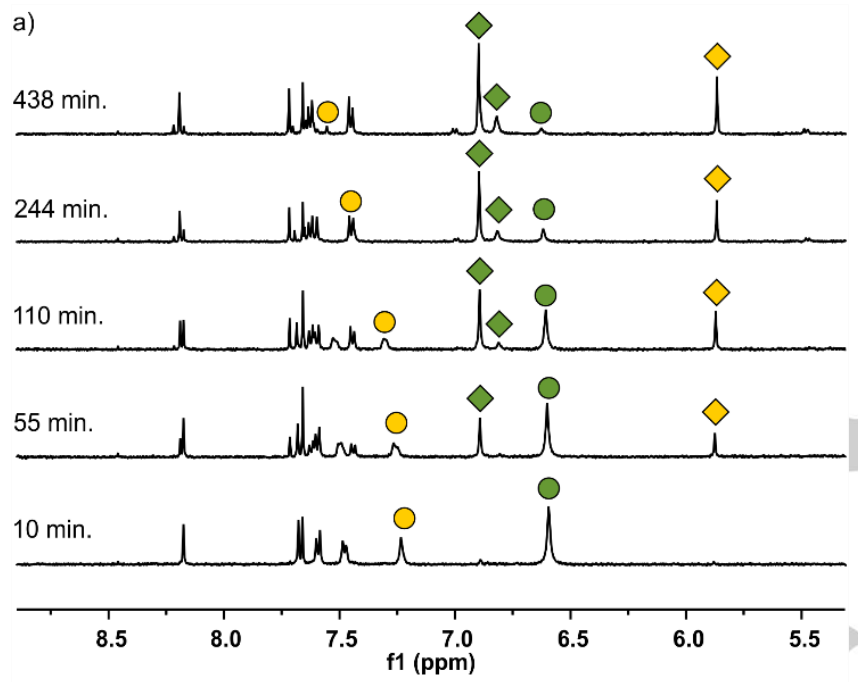

b)
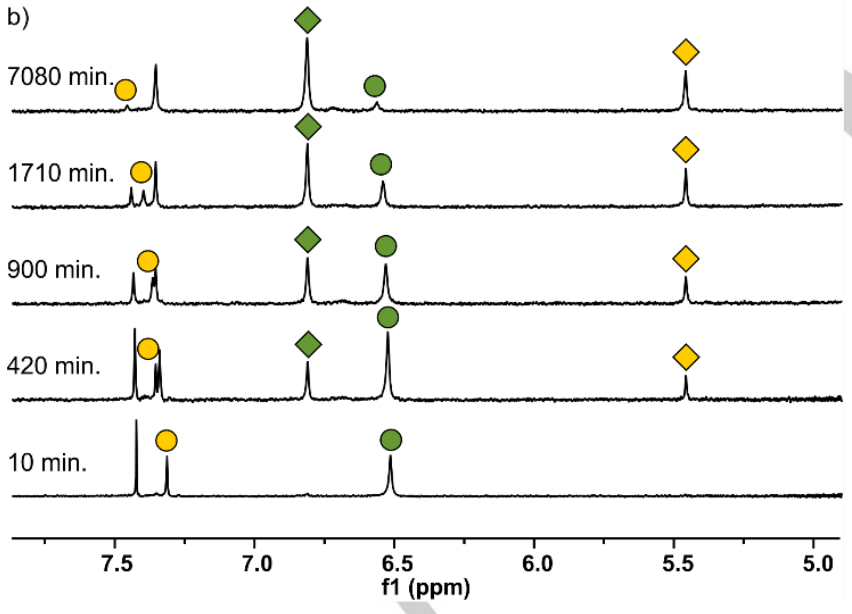

Figure 3. Slow equilibration process of the pseudorotaxane formation of 1 (a) and 2 (b) with 4 as monitored with ${ }^{1} \mathrm{H}-\mathrm{NMR}(298 \mathrm{~K}, 1: 500 \mathrm{MHz} ; 2: 400 \mathrm{MHz}$ in $\mathrm{D}_{2} \mathrm{O}$ ). Yellow circles denote the disappearing phenylene resonances of the free axles (1 and 2 ) and yellow diamonds the appearing signals of the axles in $1 \subset 4$ and $2 \subset 4$. Green circles denote the disappearing aryl resonances of the free cyclophane (4) and green diamonds the appearing signals of the cyclophane complexed as $1 \subset 4,1 \subset 4_{2}$, and $2 \subset 4$ respectively.
The formation kinetics of the pseudorotaxanes $1 \subset \mathbf{4}$ and $\mathbf{2} \subset \mathbf{4}$ were monitored by time-dependent ${ }^{1} \mathrm{H}$-NMR spectroscopy (Figure 3). Rate constants and reaction orders were determined by nonlinear least-squares fitting of time dependent concentrations. ${ }^{[42]}$ Initial experiments were conducted with equimolar concentrations $(0.5 \mathrm{mM})$ of the rods $(1$ or 2$)$ and the cyclophane 4 in $\mathrm{D}_{2} \mathrm{O}$. Interestingly, the expected second order formation kinetic was only observed for the isophthalate terminated rod 2 , while for the complexation of $\mathbf{1}$, a reasonable fit of the data was only possible for a first order kinetic. Attempts to vary the host/guest ratio of 2/4 to a point where a transition to a pseudo first order reaction occurs was not possible due to signal broadening. With the potential formation of [3]pseudorotaxanes as main difference between 1 and 2, this was the first hypothesis for the surprising first order kinetics. To suppress the formation of [3]pseudorotaxanes, the experiment was repeated with a $1(0.5 \mathrm{mM}) / 4(0.25 \mathrm{mM})$ ratio but still displayed first order kinetics, although no ${ }^{1} \mathrm{H}-\mathrm{NMR}$ signal for the formation of a [3]pseudorotaxane was observed. The halflife of cyclophane disappearance was determined to be $2.5 \mathrm{~h} \mathrm{(2:1}$ ratio) for $\mathbf{1}$ and $16 \mathrm{~h}$ for $\mathbf{2}$ with equimolar amounts of $\mathbf{4}$ at $0.5 \mathrm{mM}$ concentration. Rate constants are given in Table 1.

Table 1. Kinetic data, UV-Vis absorption and emission maxima and binding strength. Rate constants obtained from ${ }^{1} \mathrm{H}-\mathrm{NMR}$ spectra in $\mathrm{D}_{2} \mathrm{O}$. $k$-values in the first row were obtained from cyclophane disappearance, in the second row from [2]pseudorotaxane formation. Optical parameters recorded at $1 \mu \mathrm{M}$ concentrations.

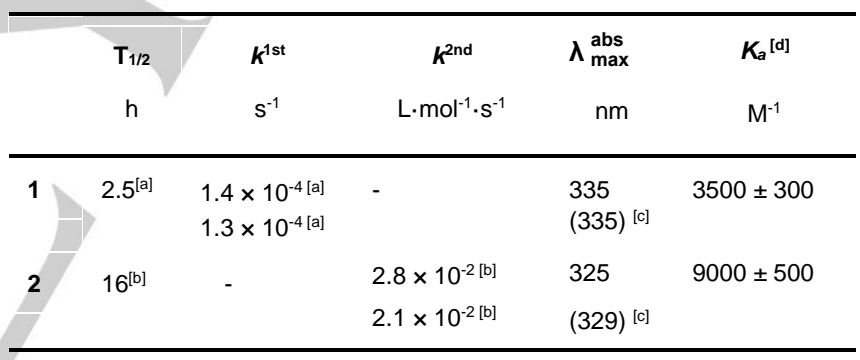

[a] $0.5 \mathrm{mM} 1+0.25 \mathrm{mM} 4$ in $\mathrm{D}_{2} \mathrm{O}$, determined by ${ }^{1} \mathrm{H}-\mathrm{NMR}$

[b] 1:1 ratio of 2 and $\mathbf{4}, 0.5 \mathrm{mM}$ in $\mathrm{D}_{2} \mathrm{O}$, determined by ${ }^{1} \mathrm{H}-\mathrm{NMR}$

[c] complex with $\mathbf{4}$ immediately measured after dilution

[d] determined in 19:1 MeOD/D $2 \mathrm{O}$

The unexpected first order kinetics observed for the formation of $\mathbf{1} \subset \mathbf{4}$ most likely arise from a fast pre-equilibrium between $\mathbf{1}$ and $\mathbf{4}$. Intuitively, the first hypothesis was a fast pre-equilibrium where the terminal triazole subunits of $\mathbf{1}$ are threaded in cyclophane $\mathbf{4}$. However, the formation of such a supramolecular complex as preequilibrium should be detectable in the chemical shift of the triazole proton immediately after the addition of 4 . Inspection of the corresponding spectra revealed a constant value for the chemical shift of the triazole signal disfavoring the hypothesis. But an immediate upfield shift by $0.45 \mathrm{ppm}$ upon addition of equimolar amounts of $\mathbf{4}$ was monitored for the protons of the central phenylene unit of 1 (Figure SI 20), pointing at a lateral aggregation of the cyclophane $\mathbf{4}$ on the rod $\mathbf{1}$ as a possible fast supramolecular pre-equilibrium. And indeed, the comparable dimensions of the extended hydrophobic backbone of $\mathbf{1}$ and the hydrophobic 
macrocycle of $\mathbf{4}$ might favor such an arrangement with the cationic piperidinium centers of $\mathbf{4}$ in close proximity of the carboxylate termini of 1. Interestingly, the electrostatic attraction between both molecules might even be maximized by the ability of rod 1 to adjust the distance between both anionic carboxylate groups by varying the torsion angles between both terminal terephthalate groups. The distance between the carboxylate termini of $\mathbf{2}$ is significantly smaller, reducing the likelihood of forming a lateral aggregate with $\mathbf{4}$. It is noteworthy however, that also for the rod 2 for which the expected $2^{\text {nd }}$ order kinetics were observed, a slight shift $(0.15 \mathrm{ppm})$ of the protons of the central phenyl unit was monitored immediately after the addition of 4 .

The significantly slower pseudorotaxane formation with the cyclophane $\mathbf{4}$ of the rods $\mathbf{1}$ and $\mathbf{2}$ compared with $\mathbf{3}$ can be explained by the increased steric demand of the additional carboxylate on the terephthalate and isophthalate terminal subunits. In particular in the rod 2 the rigid 1,2,3-substitution pattern of the isophthalate group causes a high steric barrier for complexation. The quicker $\mathbf{1} \subset \mathbf{4}$ pseudorotaxane formation compared with $\mathbf{2} \subset \mathbf{4}$ suggests that the terephthalate subunit of 1 is sterically less demanding than the isophthalate of $\mathbf{2}$. Most likely the two opposed carboxylate groups in ortho positions with respect to the rod axis allow the cyclophane to surpass both carboxylate groups in a stepwise manner.

\section{Conclusion}

On our quest for the ideal molecular axle for thermodynamically stable and kinetically slow superstructures, we identified tere- and isophthalic subunits as consummate terminal groups for OPEtype molecular axles. Both subunits increase the solubility of the axle in aqueous solution, slow down the kinetics of the supramolecular equilibration and increase the thermodynamic stability of the superstructure. Furthermore, these properties of interest can be fine-tuned by the solvent mixture employed. We are thus striving for integrating these subunits in our future rotaxane and daisy chain designs.

The potential of these units was displayed by the watersoluble model compounds $\mathbf{1}$ and $\mathbf{2}$, which are advancements of the concept of the previously reported OPE 3 . While the central, hydrophobic station and the azide decoration were maintained, the increased number of carboxylate groups improved water solubility and decelerated association kinetics with the cyclophane 4. The isophthalate-terminated rod 2 shows the slowest association kinetics and the highest stability of the pseudorotaxane $2 \subset 4$. The terephthalate-terminated rod 1 displayed faster formation kinetics and due to its extended hydrophobic backbone, it was able to form the [3]pseudorotaxane 1с42. While the pseudorotaxane formation kinetics are explained by the bulkiness of the rod's terminal groups, the stability of the superstructure is supported substantially by the electrostatic attraction between its components. An additional promising feature of the superstructures formed in water is their thermal insensitivity, further enlarging the scope of reaction conditions enabling their integration in larger architectures as well defined, mechanically integer subunits.

\section{Experimental Section}

Experimental details and synthetic procedures are given in the electronic supporting information.

\section{Acknowledgments}

Generous financial support by the Swiss Nanoscience Institute (SNI grant number P1303), the Swiss National Science Foundation (SNF grant number 200020-178808), and the VolkswagenStiftung (Az. 93438) is gratefully acknowledged. M.M. acknowledges support by the 111 project (90002-18011002).

Keywords: Supramolecular chemistry • pseudorotaxanes • cyclophanes $\bullet$ association kinetics $\bullet$ hydrophobic effect $\bullet$ watersoluble

[1] E. R. Kay, D. A. Leigh, F. Zerbetto, Angew. Chem. Int. Ed. 2007, 46, 72-191.

[2] S. Erbas-Cakmak, D. A. Leigh, C. T. McTernan, A. L. Nussbaumer, Chem. Rev. 2015, 115, 10081-10206.

[3] C. Pezzato, C. Cheng, J. F. Stoddart, R. D. Astumian, Chem. Soc. Rev 2017, 46, 5491-5507.

[4] V. Serreli, C.-F. Lee, E. R. Kay, D. A. Leigh, Nature 2007, 445, 523527.

[5] J. V. Hernandez, Science 2004, 306, 1532-1537.

[6] C. Cheng, P. R. McGonigal, W.-G. Liu, H. Li, N. A. Vermeulen, C. Ke M. Frasconi, C. L. Stern, W. A. Goddard III, J. F. Stoddart, J. Am. Chem. Soc. 2014, 136, 14702-14705.

[7] G. Ragazzon, M. Baroncini, S. Silvi, M. Venturi, A. Credi, Nat. Nanotechnol. 2015, 10, 70-75.

[8] C. Cheng, P. R. McGonigal, S. T. Schneebeli, H. Li, N. A. Vermeulen, C. Ke, J. F. Stoddart, Nat. Nanotechnol. 2015, 10, 547-553.

[9] M. R. Wilson, J. Solà, A. Carlone, S. M. Goldup, N. Lebrasseur, D. A. Leigh, Nature 2016, 534, 235-240.

[10] M. Asakawa, P. R. Ashton, R. Ballardini, V. Balzani, M. Bělohradský, M. T. Gandolfi, O. Kocian, L. Prodi, F. M. Raymo, J. F. Stoddart, J. Am. Chem. Soc. 1997, 119, 302-310.

[11] C. Heim, A. Affeld, M. Nieger, F. Vögtle, Helv. Chim. Acta 1999, 82 746-759.

[12] P. Linnartz, S. Bitter, C. A. Schalley, Eur. J. Org. Chem. 2003, 48194829.

[13] T. Oshikiri, Y. Takashima, H. Yamaguchi, A. Harada, J. Am. Chem Soc. 2005, 127, 12186-12187.

[14] P. R. McGonigal, H. Li, C. Cheng, S. T. Schneebeli, M. Frasconi, L. S. Witus, J. F. Stoddart, Tet. Lett. 2015, 56, 3591-3594.

[15] M. Hmadeh, A. C. Fahrenbach, S. Basu, A. Trabolsi, D. Benítez, H. Li, A.-M. Albrecht-Gary, M. Elhabiri, J. F. Stoddart, Chem. Eur. J. 2011, 17, 6076-6087.

[16] A. C. Catalán, J. Tiburcio, Chem. Commun. 2016, 52, 9526-9529.

[17] I. T. Harrison, J. Chem. Soc. Chem. Commun 1972, 231.

[18] P. R. Ashton, M. Bělohradský, D. Philp, N. Spencer, J. F. Stoddart, J. Chem. Soc., Chem. Commun. 1993, 1274-1277.

[19] P. R. Ashton, I. Baxter, M. C. T. Fyfe, F. M. Raymo, N. Spencer, J. F. Stoddart, A. J. P. White, D. J. Williams, J. Am. Chem. Soc. 1998, 120, 2297-2307.

[20] B. J. Slater, E. S. Davies, S. P. Argent, H. Nowell, W. Lewis, A. J. Blake, N. R. Champness, Chem. Eur J. 2011, 17, 14746-14751.

[21] Y. Yu, Y. Li, X. Wang, H. Nian, L. Wang, J. Li, Y. Zhao, X. Yang, S. Liu, L. Cao, J. Org. Chem. 2017, 82, 5590-5596.

[22] S. Tsuda, J. Terao, N. Kambe, Chem. Lett. 2009, 38, 76-77.

[23] J. Terao, S. Tsuda, Y. Tanaka, K. Okoshi, T. Fujihara, Y. Tsuji, N. Kambe, J. Am. Chem. Soc. 2009, 131, 16004-16005.

[24] J. Terao, A. Wadahama, A. Matono, T. Tada, S. Watanabe, S. Seki, T. Fujihara, Y. Tsuji, Nat. Commun. 2013, 4, 1691.

[25] H. Masai, J. Terao, S. Makuta, Y. Tachibana, T. Fujihara, Y. Tsuji, J. Am. Chem. Soc. 2014, 136, 14714-14717.

[26] H. Masai, J. Terao, T. Fujihara, Y. Tsuji, Chem. Eur. J. 2016, 22, 66246630.

[27] F. Diederich, K. Dick, D. Griebel, Chem. Ber. 1985, 118, 3588-3619.

[28] F. Diederich, Angew. Chem. Int. Ed. Engl. 1988, 27, 362-386.

[29] S. B. Ferguson, E. M. Seward, F. Diederich, E. M. Sanford, A. Chou, P. Inocencio-Szweda, C. B. Knobler, J. Org. Chem. 1988, 53, 5593-5595. 
[30] S. B. Ferguson, E. M. Sanford, E. M. Seward, F. Diederich, J. Am. Chem. Soc. 1991, 113, 5410-5419.

[31] D. R. Benson, J. Fu, Tet. Lett. 1996, 37, 4833-4836.

[32] D. R. Benson, J. Fu, C. K. Johnson, S. W. Pauls, D. A. Williamson, J. Org. Chem. 1998, 63, 9935-9945.

[33] Y. Aeschi, S. Drayss-Orth, M. Valášek, F. Raps, D. Häussinger, M. Mayor, Eur. J. Org. Chem. 2017, 4091-4103

[34] S. Anderson, R. T. Aplin, T. D. W. Claridge, T. Goodson III, A. C. Maciel, G. Rumbles, J. F. Ryan, H. L. Anderson, J. Chem. Soc. Perkin Trans. 11998, 2383-2398.

[35] P. N. Taylor, A. J. Hagan, H. L. Anderson, Org. Biomol. Chem. 2003, 1, 3851.

[36] Y. Aeschi, S. Drayss-Orth, M. Valášek, D. Häussinger, M. Mayor, Chem. Eur. J. 2019, 25, 285-295.

[37] K. D. Hänni, D. A. Leigh, Chem. Soc. Rev. 2010, 39, 1240-1251.

[38] P. R. Serwinski, P. M. Lahti, Org. Lett. 2003, 5, 2099-2102.

[39] M. C. Martos-Maldonado, I. Quesada-Soriano, J. M. Casas-Solvas, L. García-Fuentes, A. Vargas-Berenguel, Eur. J. Org. Chem. 2012, 25602571

[40] K. Barral, A. D. Moorhouse, J. E. Moses, Org. Lett. 2007, 9, 18091811.

[41] P. Thordarson, Chem. Soc. Rev. 2011, 40, 1305-1323.

[42] C. L. Perrin, J. Chem. Educ. 2017, 94, 669-672. 
WILEY-VCH

\section{COMMUNICATION}

Kinetically inert and

thermodynamically stable

pseudorotaxanes with slow formation kinetics in water are developed. The substitution pattern of the hydrophilic end-group of rigid OPE axles controls the association kinetics with a Diederich-type cyclophane.

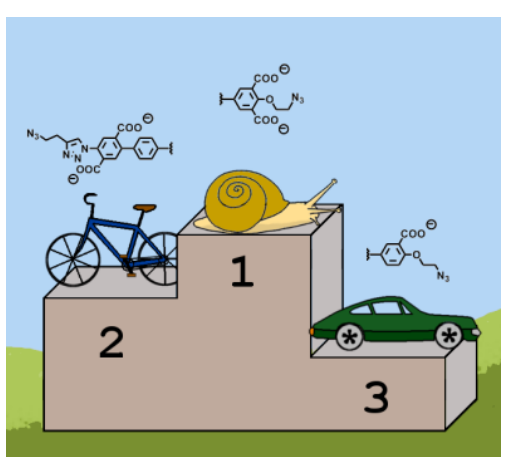

\section{Supramolecular Chemistry}

Yves Aeschi, Laurent Jucker, Daniel Häussinger, Marcel Mayor

Page No. - Page No.

Slow Formation of Pseudorotaxanes in Water 